\title{
XIX. Crystallographic notes
}

\section{W. J. Lewis M.A.}

To cite this article: W. J. Lewis M.A. (1878) XIX. Crystallographic notes, Philosophical Magazine Series 5, 5:29, 139-144, DOI: 10.1080/14786447808639399

To link to this article: http://dx.doi.org/10.1080/14786447808639399

$$
\text { 曲 Published online: } 13 \text { May } 2009 .
$$

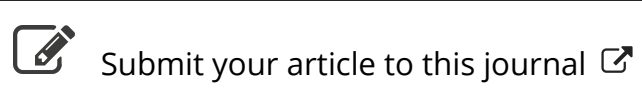

\footnotetext{
山 Article views: 2
}

Q View related articles $\sqsubset$ 
Which form of Daniell's element Bosscha used, unfortunately he does not state; but we may assume as extremely probable that he made use of the form ordinarily employed, to which, according to my measurements, belongs the absolute electromotive force

$$
11 \cdot 30 \times 10^{10}\left(\frac{\text { millim. } .^{\frac{3}{2}} \operatorname{milligr} \cdot \frac{1}{2}}{\text { sec. }^{2}}\right) .
$$

This value is greater, in the ratio of $1 \cdot 1016$ to $1 \cdot 0000$, than that deduced by Bosscha. Now, supposing that Bosscha has carried out his measurements free from error (a supposition which of course cannot be rigorously correct), then the absolute value of the resistance taken by him as the basis of his measurements, $i$. $e$. the absolute value found by W. Weber for Jacobi's unit, would be 10.16 per cent. too little.

This calculation of the error is based on two somewhat uncertain assumptions, briefly indicated above. On this account it is a great advantage that an error in W. Weber's determination of the absolute resistance of Jacobi's unit, in the same direction and of the same order of magnitude, can be deduced in quite another way. According to $W$. Siemens the ratio of Jacobi's resistance-unit to Siemens's is $=0 \cdot 6618$. From our numerous and multifariously varied measurements the absolute value of the Siemens unit is $0.9550 \times 10^{10}\left(\frac{\text { millim. }}{\text { sec. }}\right)$. Accordingly the absolute value of Jacobi's resistance-unit would be, from our measurements, $0.6320 \times 10^{10}\left(\frac{\text { millim. }}{\text { sec. }}\right)$; while M. Wilh. Weber found only $0.598 \times 10^{10}$ ( $\left.\frac{\text { millim. }}{\text { sec. }}\right)$-that is, a value about 6 per cent. less than that found by us.

Hence the absolute measurement by M. W. Weber of Jacobi's resistance-unit has turned out certainly from 6 to 10 per cent. too little.

[To be continued.]

XIX. Crystallographic Notes.

$B y$ W. J. Lewis, M.A., Fellow of Oriel College, Oxford*.

D. HUGO MÜLLER had the goodness, some time ago, to send me some crystals of the isomerous compounds Quercite and Inosite, which he had obtained from new sourcesthe former from the leaves of the dwarf-palm (Chamarops humilis), and the latter from cochineal.

* Communicated by the Crystallological Society, having been read October 26, 1877. 
Quercite.-The crystallography of Quercite has been already determined by Sénarmont (Rammelsberg's Die neuesten Forschungen in der Krystall-Chemie); but it was a matter of interest to determine whether any difference either in habit or angles could be found in the crystals obtained from the new source. The crystals were found to show the same hemimorphous habit (fig. 1) observed by Sénarmont; and but a slight change has been made in the elements, which may probably be explained by the fact that the crystals obtained by Dr. Müller were very perfect.

The crystal is positive; the optic axes lie in the plane of symmetry; the mean line lies between $c$ and $g$, and makes an angle of about $20^{\circ}$ with the normal to $g$, the dispersion (inclinée) being considerable, $v>\rho$. The angles of the optic axes in air for the red and blue rays were found to be $55^{\circ} 17^{\prime}$ and $58^{\circ} 20 \frac{1}{2}^{\prime}$ respectively.

Fig. 1.

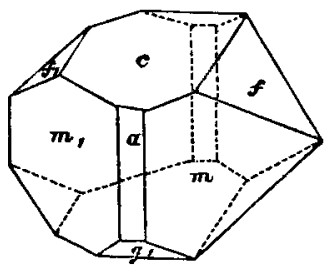

Fig. 2.

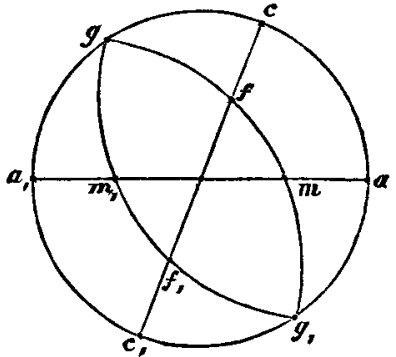

The forms observed are $a\{100\}, m\left\{\begin{array}{lll}1 & 1 & 0\end{array}, c\left\{\begin{array}{lll}0 & 0 & 1\end{array}\right\}, f\left\{\begin{array}{lll}0 & 1 & 1\end{array}\right\}\right.$, $g\left\{\begin{array}{lll}\overline{1} & 0 & 1\end{array}\right\}$ (fig. 2). The faces of the prism are striated parallel to their intersection with $a$; and there is a good cleavage

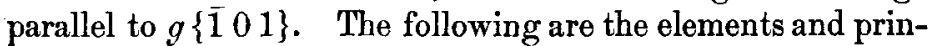
cipal angles observed and calculated.

$$
\begin{gathered}
(100,101)=35^{\circ} 32^{\prime} \cdot 2,(101,001)=33^{\circ} 30^{\prime} \cdot 8, \\
(010,111)=66^{\circ} 1^{\prime} . \\
a: b: c=1: 1 \cdot 241: 0 \cdot 95 .
\end{gathered}
$$

Calculated. Observed.

\begin{tabular}{|c|c|c|c|c|}
\hline$\left[\begin{array}{l}a c \\
c g \\
g a\end{array}\right.$ & $\begin{array}{rc}* 6 \stackrel{\circ}{3} & \text { u } \\
53 & 20 \frac{1}{3} \\
* 57 & 36 \frac{2}{3}\end{array}$ & $\begin{array}{lc}69 & 5 \\
53 & 161 \\
57 & 35\end{array}$ & $68^{\circ} 57$ & $\begin{array}{ll}68 & 57 \\
53 & 22 \\
57 & 20\end{array}$ \\
\hline$\left[\begin{array}{l}c f \\
f f\end{array}\right.$ & $\begin{array}{ll}* 35 & 33 \frac{1}{2} \\
108 & 53\end{array}$ & $\begin{array}{rl}35 & 32 \\
108 & 49 \frac{1}{2}\end{array}$ & $\begin{array}{rr}35 & 34 \\
108 & 52\end{array}$ & $\begin{array}{rr}35 & 32 \\
109 & 5\end{array}$ \\
\hline
\end{tabular}

Sénarmont.

Calculated. Observed. 
Table (continued).

Calculated. Observed. $\overbrace{\text { Calculated. Observed. }}^{\text {Sénarmont. }}$

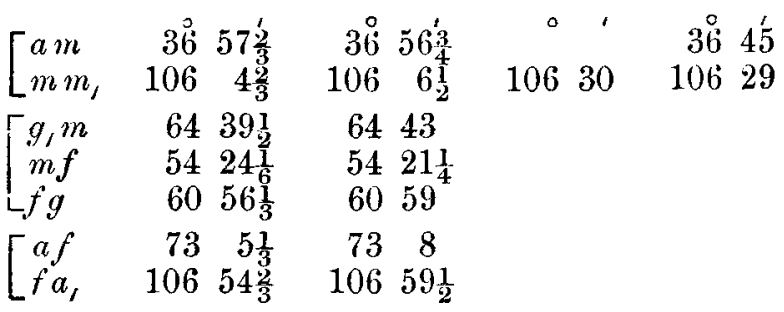

Inosite.-This substance crystallizes in colourless, much striated prisms, attached by one end to the mass of the substance. The striations on the planes lying in the prism-zone rendered it impossible, even in the most delicate needles, to get reliable measurements of the angles in this zone. The prisms were terminated by four small planes, $\left\{\begin{array}{lll}1 & 0 & \overline{1}\end{array}\right\},\left\{\begin{array}{lll}1 & 0 & 1\end{array}\right\}$, and $\{012\}$, of which the former was most largely developed, sometimes even to the exclusion of the other planes. The crystals were extremely friable, and lost a portion of their water very readily-properties which rendered the examination difficult and prevented the determination of their optical character. The opposite faces in the zones were in all cases considerably displaced, so that there was always a divergence from the zore and from $180^{\circ}$ in the sum of the angles between them. The following elements and measurements can therefore only ke regarded as approximate.

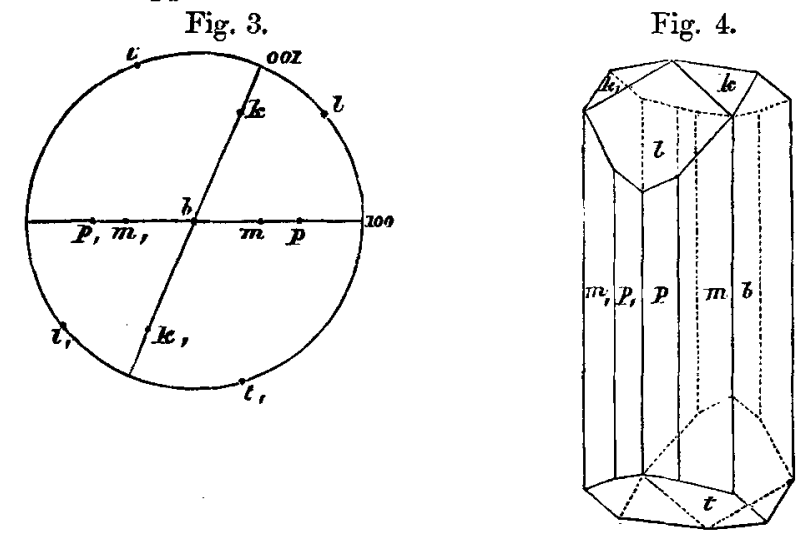

The system is oblique. The forms are $b\{010\}, m\{110\}$, $p\{210\},\left\{\begin{array}{lll}4 & 0 & 0\end{array}, l\left\{\begin{array}{lll}1 & 0 & 1\end{array}\right\}, t\left\{\begin{array}{lll}1 & 0 & 1\end{array}\right\}, k\left\{\begin{array}{lll}0 & 1 & 2\end{array}\right\}\right.$ (fig, 4 ). 


$$
\begin{gathered}
(100,101)=40^{\circ} 51 \frac{3^{\prime}}{4}, \quad(101,001)=28^{\circ} 273^{\prime}, \\
(010,111)=62^{\circ} 452^{\prime} ; \\
a: b: c=1.0802: 1: 0 \cdot 7869 .
\end{gathered}
$$

\begin{tabular}{|c|c|}
\hline $\begin{array}{l}l t \\
l k \\
t k\end{array}$ & $\begin{array}{ll}71^{\circ} & 0^{\prime} \\
34 & 24 \frac{1}{2} \\
46 & 15\end{array}$ \\
\hline$\left[\begin{array}{l}b m \\
b p \\
b(410) \\
m m\end{array}\right.$ & $\begin{array}{ll}44 & 42 \\
63 & 11 \frac{1}{2} \\
75 & 49 \frac{1}{2} \\
89 & 24\end{array}$ \\
\hline$\left[\frac{m}{m} l\right.$ & $\begin{array}{rr}57 & 51 \frac{2}{3} \\
122 & 8 \frac{1}{3}\end{array}$ \\
\hline$\left[\begin{array}{l}m, t \\
m, t\end{array}\right.$ & $\begin{array}{rr}74 & 49 \\
105 & 11\end{array}$ \\
\hline$\left[\begin{array}{l}m \\
m \\
k\end{array}\right.$ & $\begin{array}{rr}61 & 24 \frac{1}{3} \\
118 & 35 \%\end{array}$ \\
\hline $\begin{array}{l}m_{l} k \\
b l\end{array}$ & $\begin{array}{rr}89 & 17 \\
90 & 0\end{array}$ \\
\hline 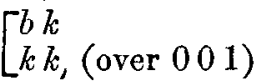 & $\begin{array}{ll}69 & 47 \frac{1}{2} \\
40 & 25\end{array}$ \\
\hline
\end{tabular}

Calculated.
Observed.

$70^{\circ} 3 \dot{4} \frac{1}{2}$ to 7027 3436,3414 $4611 \% 45 \quad 54$ 4450,4436 $\begin{array}{lllll}63 & 13 & 962 & 52\end{array}$ $\begin{array}{lllll}76 & 0 & & 75 & 45\end{array}$ 8937

5756

$12149 \frac{1}{2}$

$\begin{array}{rrrrr}74 & 58 & , 74 & 52 \\ 105 & 6 & , 105 & 10 \\ 61 & 52 & & 61 & 34 \\ 118 & 10 & & \\ & & & \\ 89 & 53 \frac{1}{2} & & \\ 69 & 32 & 70 & 3 \frac{1}{2} \\ 40 & 13\end{array}$

Jordanite.-On a crystal of blende from the Binnenthal in the British Museum two small crystals, the one of Jordanite, the other of Binnite, are implanted. The former, on measure-

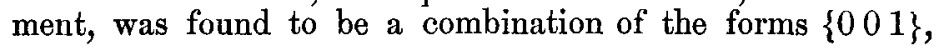
$\{119\},\{113\},\{225\},\{112\},\{110\},\{013\},\{025\}$, $\{012\},\{023\},\{011\},\{312\},\{311\},\{310\}$. Of these the forms $\{225\},\{025\},\{023\},\{312\},\{310\}$ are, I believe, new. The middle index in these symbols corresponds to the brachydiagonal usually denoted by the letter $y$ and the parameter $b$. This arrangement is not to be confounded with that of Professor vom Rath, in which $b$ corresponds to the makrodiagonal and $a$ to the brachydiagonal. The angles between some of these planes observed and calculated from the elements, $c: \frac{1}{2} o=65^{\circ} 0^{\prime} ; \frac{1}{2} o: \frac{1}{2} o=50^{\circ} 49^{\prime}$, given by Prof. vom Rath are :- 


\begin{tabular}{|c|c|c|c|}
\hline & $\begin{array}{l}\text { v. Rath's } \\
\text { notation. }\end{array}$ & Calculated. & Observed. \\
\hline$-001: 013$ & $c: \frac{1}{3} d$ & 5133 & 5133 \\
\hline $001: 025$ & & $56 \quad 30 \frac{1}{3}$ & not determined. \\
\hline $001: 012$ & $c: \frac{1}{2} d$ & $62 \quad 6 \frac{1}{6}$ & $62 \quad 6$ \\
\hline $001: 023$ & & $68 \quad 20 \frac{2}{3}$ & 6823 \\
\hline L001:011 & $c: d$ & $\begin{array}{lll}75 & 10_{2}^{1}\end{array}$ & $75 \quad 6$ \\
\hline$\Gamma 001: 312$ & & $74 \quad 24 \frac{1}{2}$ & 7415 \\
\hline $001: 311$ & $c: u$ & $82 \quad 3 \frac{1}{2}$ & 8147 \\
\hline L001:310 & & $90 \quad 0^{2}$ & 8955 \\
\hline$\lceil 312: 112$ & & 2932 & 2930 \\
\hline$[112: 012$ & $\frac{1}{2} o: \frac{1}{2} d$ & $25 \quad 24 \frac{1}{2}$ & $25 \quad 27$ \\
\hline
\end{tabular}

The plane (112) was the largest plane on the crystal, $\left(\begin{array}{lll}0 & 0 & 1\end{array}\right)$ the next. All the other planes were small ; and some thin twin laminæ were observed intersecting the zones [0 01 ,

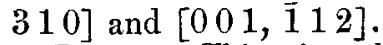

Binnite.-This mineral has occupied the attention of several mineralogists, a summary of whose work on it is given by Hessenberg in his Min. Notizen, ix., where he describes a very beautiful specimen in his possession. Kenngott, after an examination of the crystals in Wiser's collection, came to the conclusion that the mineral was hemihedral, a conclusion combated by von Waltershausen. After a careful study of the distribution of the faces on his crystal, Hessenberg comes to a conclusion opposed to that of Kenngott; for although the forms $\{111\},\{211\},\{321\},\{411\}$, and $\{10,1,1\}$ were incomplete, he found that the faces of $\{111\},\{211\}$, and $\{321\}$ were present in an irregular manner. He has made no remark, however, on the fact that the faces of $\{411\}$ and $\{10,1,1\}$ are present in adjacent octants only.

In the examination of the specimen in the British Museum, especial attention was paid to the distribution of the faces of the different forms. It consists of two crystals united together in parallel positions, or possibly of one crystal whose free development has been prevented at one point by the presence of

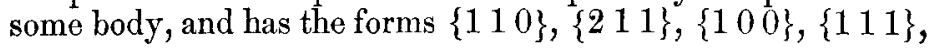
$\{321\}, \kappa\{411\}, \kappa\{611\}, \kappa\{711\}, \kappa\{10,11\}$, and $\kappa\{233\}$, of which $\kappa\{711\}$ is new. The forms $\{110\},\{211\}$ are well and about equally developed; the others are subordinate. The number of octants which could be examined was six; so that the question of the hemihedrism could be more thoroughly tested than it was by Hessenberg, who was only able to examine four. The forms $\left\{\begin{array}{lll}1 & 1 & 0\end{array},\left\{\begin{array}{lll}2 & 1 & 1\end{array}\right\}\right.$ were well developed in adjacent octants, and are therefore holohedral. The forms 
$\{411\},\{611\},\{711\},\{10,11\}$, and $\{233\}$ were found in alternate octants only, and are consequently hemihedral. The faces of $\{321\}$ were for the most part badly developed, and did not permit of any certain conclusion being drawn. Hessenberg found a plane of the form in each of two adjacent octants which excludes a hemihedrism with inclined faces. I believe it, from my observations, to be holohedral. A further examination of such crystals as are to be found in the various collections might possibly set the question of the hemihedrism of the mineral at rest, and would certainly be interesting.

XX. Short Reports from the Chemical Laboratory of Trinity College, Dublin. By J. Emerson-Reynolds, M.D., Professor of Chemistry, University of Dublin *.

No. 5. On the Rapid Estimation of Urea.

A DIS'IINGUISHED physician, who wished to make A frequent determinations of the urea daily excreted by a patient, requested me to devise a method which would enable him to make the desired estimation-(a) rapidly, (b) with sufficient accuracy for ordinary clinical purposes, $(c)$ with simple and easily constructed apparatus, and $(d)$ without the use of a balance or of any measuring-vessels other than the fluid-ounce and minim measures which a medical man is in the habit of employing.

This interesting practical problem was solved in the manner I shall presently describe; and the results obtained by the use of the method devised have been so satisfactory as to lead me to expect that it may be found generally useful where a high degree of accuracy is not desired.

I propose, however, before concluding this paper, to describe a less simple plan for the estiniation of urea than that just referred to, but one which is capable of affording results of greater precision.

In both the methods mentioned I take advantage of the now well-known reaction of sodic hypobromite with urea. When a strongly alkaline solution of sodic hypobromite is added to a liquid containing urea, the latter suffers rapid decomposition into water, carbonic anhydride, and pure nitrogen gas. The carbonic anhydride is not evolved as gas, but is absorbed, with formation of sodic carbonate, by the free alkali of the liquid used to effect decomposition; the nitrogen is evolved in the gaseous condition, and its bulk determined either indirectly or

* From the Scientific Proceedings of the Royal Dublin Society. Communicated by the Author. 